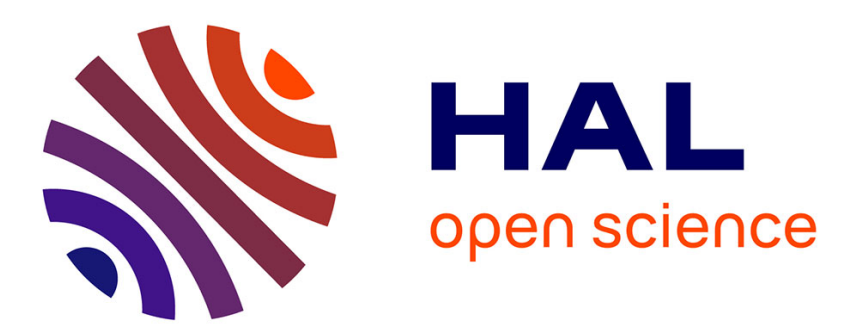

\title{
The non-chondritic Ni isotope composition of Earth's mantle
}

\author{
Martijn Klaver, Dmitri Ionov, Eiichi Takazawa, Tim Elliott
}

\section{To cite this version:}

Martijn Klaver, Dmitri Ionov, Eiichi Takazawa, Tim Elliott. The non-chondritic Ni isotope composition of Earth's mantle. Geochimica et Cosmochimica Acta, 2020, 268, pp.405-421. 10.1016/j.gca.2019.10.017 . hal-02445427

\section{HAL Id: hal-02445427 \\ https://hal.umontpellier.fr/hal-02445427}

Submitted on 16 Apr 2021

HAL is a multi-disciplinary open access archive for the deposit and dissemination of scientific research documents, whether they are published or not. The documents may come from teaching and research institutions in France or abroad, or from public or private research centers.
L'archive ouverte pluridisciplinaire HAL, est destinée au dépôt et à la diffusion de documents scientifiques de niveau recherche, publiés ou non, émanant des établissements d'enseignement et de recherche français ou étrangers, des laboratoires publics ou privés. 


\section{The non-chondritic Ni isotope composition of Earth's mantle}

\section{Martijn Klaver ${ }^{1 *}$, Dmitri A. Ionov ${ }^{2}$, Eiichi Takazawa ${ }^{3}$ and Tim Elliott ${ }^{1}$}

$3{ }^{1}$ Bristol Isotope Group, School of Earth Sciences, University of Bristol. Wills Memorial Building, Queen's Road,

4 Bristol BS8 1RJ, United Kingdom

${ }^{2}$ Géosciences Montpellier, Université de Montpellier, 34095 Montpellier, France

${ }^{3}$ Department of Geology, Faculty of Science, Niigata University, 2-8050 Ikarashi, Nishi-ku, Niigata, 950-2181, Japan

*corresponding author. Current address: School of Earth and Ocean Sciences, Cardiff University, UK; klaverm@cardiff.ac.uk

\section{ABSTRACT}

Nickel is a major element in the Earth. Due to its siderophile nature, $93 \%$ of $\mathrm{Ni}$ is hosted in the core and the $\mathrm{Ni}$ isotope composition of the bulk silicate Earth might inform on the conditions of terrestrial core formation. Whether Earth's mantle is fractionated relative to the chondritic reservoir, and by inference to the core, is a matter of debate that largely arises from the uncertain $\mathrm{Ni}$ isotope composition of the mantle. We address this issue through high-precision $\mathrm{Ni}$ isotope measurements of fertile- to melt-depleted peridotites and compare these data to chondritic meteorites. Terrestrial peridotites that are free from metasomatic overprint display a limited range in $\delta^{60 / 58} \mathrm{Ni}$ (deviation of ${ }^{60} \mathrm{Ni} /{ }^{58} \mathrm{Ni}$ relative to NIST SRM 986) and no systematic variation with degree of melt depletion. The latter is consistent with olivine and orthopyroxene buffering the Ni budget and isotope composition of the refractory peridotites. As such, the average $\mathrm{Ni}$ isotope composition of these peridotites $\left(\delta^{60 / 58} \mathrm{Ni}=0.115 \pm 0.011 \%\right.$ ) provides a robust estimate of the $\delta^{60 / 58} \mathrm{Ni}$ of the bulk silicate Earth. Peridotites with evidence for melt metasomatism range to heavier $\mathrm{Ni}$ isotope compositions where the introduction of clinopyroxene appears to drive an increase in $\delta^{60 / 58} \mathrm{Ni}$. This requires a process where melts do not reach isotopic equilibrium with buffering olivine and orthopyroxene, but its exact nature remains obscure. Chondritic meteorites have variability in $\delta^{60 / 58} \mathrm{Ni}$ due to heterogeneity at the sampling scale. In particular, $\mathrm{Cl} 1$ chondrites are displaced to isotopically lighter values due to sorption of $\mathrm{Ni}$ onto ferrihydrite during parent body alteration. Chondrites less extensively altered than the $\mathrm{Cl} 1$ chondrites show no systematic differences in $\delta^{60 / 58} \mathrm{Ni}$ between classes and yield average $\delta^{60 / 58} \mathrm{Ni}=0.212 \pm 0.013 \%$, which is isotopically heavier than our estimate of the bulk silicate Earth. The notable isotopic difference between the bulk silicate Earth and chondrites likely results from the segregation of the terrestrial core. Our observations potentially provide a novel constraint on the conditions of terrestrial core formation but requires further experimental calibration.

\section{Introduction}


The segregation into a metallic core and silicate mantle is the largest differentiation event in Earth's history, yet the exact conditions under which metal-silicate segregation took place remain incompletely understood, despite a long history of elemental partitioning studies (cf., Wade and Wood, 2005; Siebert et al., 2013). Massdependent ("stable") isotope fractionation provides an alternative approach to investigate core formation (e.g., Schoenberg and von Blanckenburg, 2006; Georg et al., 2007; Fitoussi et al., 2009; Polyakov, 2009). Establishing the relative isotopic compositions of the core and the bulk silicate Earth (BSE) is the first step in this approach. As the core is inaccessible for direct sampling, its isotopic composition cannot be determined directly. For refractory elements that are not isotopically fractionated during planetary accretion, however, the composition of the core can be estimated through a mass balance between the BSE and chondritic meteorites that are inferred to be representative of the bulk Earth.

The mass-dependent isotope systematics of a range of elements has been investigated to find a core formation signature, but results have so far been inconsistent and subject to multiple interpretations (see Bourdon et al., 2018 for a recent review). Nickel is the fifth most abundant element in the Earth and holds considerable promise as an isotopic tracer of core formation yet has received comparatively little attention to date. Its elemental distribution between the mantle and core has been pivotal in demonstrating high-pressure core formation on Earth (e.g., Li and Agee, 1996) and is optimal for its use as a core formation proxy. Nickel is sufficiently siderophile to yield a large potential isotopic difference between the BSE and chondrites but not to the extent that its mantle budget is significantly overprinted by a late-veneer component ( $<5 \%$ of mantle $\mathrm{Ni}$ derives from a late veneer addition corresponding to $0.6 \%$ of the mass of the Earth). Compared to Fe, which has a similar core-mantle partition coefficient, $\mathrm{Ni}$ has the distinct advantage that it occurs in a single valence state in the mantle. This eliminates a significant layer of complexity compared to $\mathrm{Fe}$, whose two valence states can induce significant isotope fractionation during mantle processes such as the disproportionation of $\mathrm{Fe}^{2+}$ by bridgmanite (Williams et al., 2012) and partial melting (Weyer et al., 2005; Dauphas et al., 2009).

To use $\mathrm{Ni}$ isotopes as a tracer of core formation requires a comparison of well-constrained isotopic compositions of the BSE and chondritic meteorites. Clear deductions from published Ni data are obfuscated by much scatter but a recent compilation hints at an isotopically light BSE (Elliott and Steele, 2017). Whereas previous studies have reported relatively consistent $\mathrm{Ni}$ isotope compositions for chondrites and iron meteorites (Cook et al., 2007; Moynier et al., 2007; Cameron et al., 2009; Chernonozhkin et al., 2016; Gall et al., 2017), the $\mathrm{Ni}$ isotope composition of the BSE is more contentious (Cameron et al., 2009; Gueguen et al., 2013; Gall et al., 2017). Much of the uncertainty in estimates of the composition of the BSE can arise from the inclusion of basalts and komatiites, which might be isotopically fractionated relative to their mantle source by the presently unconstrained olivine-melt fractionation factor. A detailed study of $\mathrm{Ni}$ isotope variation in fertile, nonmetasomatised peridotites, which provide the best approximation of the BSE (Carlson and lonov, 2019), is currently lacking.

In this contribution, we re-evaluate the $\mathrm{Ni}$ isotope composition of the BSE through high-precision isotope measurements of four carefully selected suites of mantle peridotites. These samples cover a wide range in degrees of melt depletion and are minimally affected by metasomatic overprint. For five of these unmetasomatised peridotites, we have also measured the Ni isotope composition of pristine olivine separates. 
In addition, five peridotite samples with evidence for modal or cryptic metasomatism were included to specifically investigate the effects of melt-rock reactions in the mantle. We complement the peridotite dataset with measurements of chondritic meteorites to compare mantle- and chondrite $\mathrm{Ni}$ isotope compositions obtained using the same methodology.

\section{Peridotite and meteorite samples}

\subsection{Peridotite samples}

We focus on well-characterised orogenic peridotites from the Horoman (Japan) and Zabargad (Red Sea) massifs and Central-Asian off-cratonic peridotite xenoliths (Vitim and Tariat) to investigate Ni isotope variations in the mantle and obtain an improved estimate of the $\mathrm{Ni}$ isotope composition of the BSE. Many of these samples have been used previously to constrain the mass-dependent isotope composition of the BSE for e.g., Li, Mg, Ca, V, Cr and Fe (Weyer and lonov, 2007; Pogge von Strandmann et al., 2011; Hin et al., 2017; Kang et al., 2017; Xia et al., 2017; Qi et al., 2019). There are several important reasons behind our choice of these sample sets. As weathering of peridotites has been shown to drive fractionation of Ni isotopes (e.g., Ratié et al., 2015; SpivakBirndorf et al., 2018), freshness of the samples was a first prerequisite.

The second criterion was to minimise the effect of metasomatic overprints by selecting peridotites without petrographic evidence for metasomatism such as the introduction of secondary clinopyroxene, garnet or other phases. The lack of metasomatic perturbance of the selected samples is supported by chemical and radiogenic isotope evidence (e.g., Saal et al., 2001; Ionov et al., 2005; Carlson and lonov, 2019). For example, fertile to moderately melt-depleted samples have primitive mantle-normalised (PM; Palme and O'Neill, 2014) flat to light rare earth element (LREE) depleted trace element patterns (Figure 1) and superchondritic ${ }^{143} \mathrm{Nd} /{ }^{144} \mathrm{Nd}$. The most refractory (highest $\mathrm{MgO}$ content) samples show variable fluid-mobile element enrichment (e.g., Takazawa et al., 2000), indicative of minor cryptic metasomatism, yet still have La/SmPM $\leq 1$ and are not overprinted to the extent seen in cratonic xenoliths (supplementary Figure S1).

Furthermore, the majority of the peridotites have been previously measured for their Li isotope composition (Brooker et al., 2004; Pogge von Strandmann et al., 2011; Lai et al., 2015) so that we can explicitly avoid samples affected by kinetic fractionation resulting from diffusional disturbance during xenolith entrainment or as a result of melt percolation, which might possibly affect $\mathrm{Ni}$ isotope systematics in a similar manner to Mg (Pogge von Strandmann et al., 2011; see Figure 1).

Our set of peridotite samples includes garnet-, spinel- and plagioclase peridotites that record a wide range in degree of melt depletion (e.g., 37-49 wt.\% MgO; Figure 1). This allows us to investigate the possible influence of melt depletion on the $\mathrm{Ni}$ isotope composition of refractory peridotites. Nevertheless, our collection still includes a large number of fertile samples, not well represented in previous $\mathrm{Ni}$ isotope studies, that provide the readiest estimate for the $B S E$.

Although the focus of this study is on non-metasomatised peridotites, we have included five samples with obvious evidence for melt metasomatism as indicated by the introduction of clinopyroxene or La/SmPM $>1$ 
114 (Figure 1), to assess the influence of melt-rock reactions on $\mathrm{Ni}$ isotope systematics. The metasomatised samples

115 include a Zabargad Iherzolite with modal clinopyroxene enrichment and high $\delta^{7} \mathrm{Li}$ (BZ-230). In addition, LREE

116 enrichment in four Tariat xenoliths points to a more cryptic metasomatic overprint, and phlogopite is also

117 present in one of these samples. A more detailed description of the peridotite samples is provided in the online 118 supplementary material.

119

120

121

122

123

124

125

126

127

128

129

130

131

132

133

134

135

136

137

138

139

140

141

142

143

144

145

146

147

148

\section{Analytical techniques}

149

150

\subsection{Chondritic meteorites} deserts or Antarctica.

A diverse set of 25 chondritic meteorites of different petrological grades was measured for their Ni isotope composition. This sample set includes seven ordinary chondrites (LL3.6-LL6, L3.7-L4 and H4), eight enstatite chondrites (EH3-EH5 and EL6) and ten carbonaceous chondrites (CI1, CM2, CR2, CO3, CV3 and CK4). Small samples of the chondritic meteorites, weighing between 4 and $100 \mathrm{mg}$, where provided by the Natural History Museum (NHM; London); see Table 2 for identification numbers and dissolved weights. Larger pieces of three additional ordinary chondrites (Chelyabinsk, Kilabo and Buzzard Coulee) and a sample of carbonaceous chondrite Allende were obtained from meteorite dealers. Small chips from the interior of these meteorites were lightly crushed in an agate pestle and mortar before further processing.

The majority of the chondrites used in this study are observed falls, thus limiting the extent of terrestrial weathering and contamination. The four exceptions are Barratta (H4), Yilmia (EL6), Atlanta (EL6) and Kota-Kota (EH3). Of these meteorite finds, Barratta was recovered approximately 12 years after falling on Earth and is fresh with a well-preserved fusion crust (Mason and Wiik, 1966). Yilmia, another Australian find, is locally extensively weathered but retains fresh sections in the centre (Buseck and Holdsworth, 1972). The specimen in the NHM collection is derived from the centre and essentially unweathered. For Kota-Kota and Atlanta, we did not process bulk samples but microdrilled mounts of these meteorites to explicitly target the most pristine parts of the meteorite samples (recovery of $\sim 5-10 \mathrm{mg}$ sample material; Table 2). We have, however, specifically avoided meteorite finds with a long terrestrial residence time, such as finds from the Sahara and Arabian

As heterogeneous objects, Jarosewich (1990) recommends that a minimum of $10 \mathrm{~g}$ of chondrite material should be used for a representative chemical analysis. Due to the precious nature of meteoritic material, this is not practically possible and we have performed measurements on significantly smaller aliquots, as common in many studies. In order to assess the effect of a sampling bias on our $\mathrm{Ni}$ isotope measurements, we have measured two separate samples of $\mathrm{Cl} 1$ chondrite Orgueil (both provided by the NHM). In addition, we have measured both a bulk sample $(46.7 \mathrm{mg})$ of L3.7 chondrite Ceniceros and four subsamples microdrilled from two polished mounts (5-10 mg material; see Luu et al., 2019 and Table 2 for more details).

\subsection{Digestion and Ni purification}



dissolutions that were measured for Mg isotope composition by Hin et al. (2017) and Luu et al. (2019). Peridotite and additional meteorite samples were digested in $\mathrm{HF}-\mathrm{HNO}_{3}$ at $200^{\circ} \mathrm{C}$ and high-pressure in PTFE bombs. Initially, several peridotite samples were digested at low pressure and $140^{\circ} \mathrm{C}$ but this proved insufficient to break down spinel in spinel-rich samples. When residual spinel was present (e.g., in DTS-1), a

156

157

158

159

160

161

162

163

164

165

166

167

168 new sample aliquot was digested at high pressure. Several Horoman peridotites did dissolve completely at low pressure and Ni data for low- and high-pressure digestions of DTS-1 (with and without residual spinel) yield indistinguishable results (Figure 2).

After digestion, an aliquot of each sample solution was equilibrated with a ${ }^{61} \mathrm{Ni}-{ }^{62} \mathrm{Ni}$ double spike prior to further processing. The double spike was calibrated as described in Klaver and Coath (2019). Nickel was separated from the matrix using a two-step ion-exchange procedure. A brief outline of the purification procedure is presented below; additional information is provided in the online supplementary material. The first step employs high-aspect ratio columns with $2.5 \mathrm{~mL}$ AG50W-X12 resin used for Mg separation (Pogge von Strandmann et al., 2011). Nickel and $\mathrm{Mg}$ are co-eluted from this column in $2.00 \mathrm{M} \mathrm{HNO}_{3}$ whereas most other major cations are effectively separated; $\mathrm{Ti}, \mathrm{Al}$ and Fe are eluted with $0.5 \mathrm{M} \mathrm{HF}$ and $\mathrm{Ca}$ and $\mathrm{Cr}$ remain on the column. The Mg-Ni fraction only contains $\mathrm{Mn}, \mathrm{Co}$ and $\mathrm{K}$. Subsequent Ni purification was achieved using cationic resin with a mixed $\mathrm{HCl}$-acetone eluent and dimethylglyoxime as a $\mathrm{Ni}$-specific chelating agent (Wahlgren et al., 1970; Victor, 1986).

The use of dimethylglyoxime has been successfully used in other protocols for separating Ni (e.g., Regelous et al., 2008; Chernonozhkin et al., 2015) but quantitative break-down of the organic Ni complex is potentially problematic and can affect the magnitude of instrumental mass fractionation during measurement (Klaver and Coath, 2019). Hence, we minimise the amount of dimethylglyoxime by using it only in a final smallvolume ( $200 \mu \mathrm{L} ; 4.5$ by $13 \mathrm{~mm}$ ) column filled with AG50W-X4 resin. The Ni-Mg fraction from the first column was dissolved in $50 \mu \mathrm{L} 10 \mathrm{M} \mathrm{HCl}$ to which $950 \mu \mathrm{L}$ Romil SpS quality acetone was added while columns were conditioned with $1 \mathrm{~mL} 0.5 \mathrm{M} \mathrm{HCl}-95 \%$ acetone. After loading, Mn, Co and any residual Fe were eluted with 600 $\mu \mathrm{L} 0.5 \mathrm{M} \mathrm{HCl}-95 \%$ acetone. Nickel was collected with $1.5 \mathrm{~mL} \mathrm{0.5} \mathrm{M} \mathrm{HCl-95 \%} \mathrm{acetone-0.1} \mathrm{M} \mathrm{dimethylglyoxime}$ and 0.5-1.0 mL 0.5 M HCl-95\% acetone; $\mathrm{Mg}$ and any other remaining matrix elements were rinsed off the column with $6 \mathrm{M} \mathrm{HCl}$. The Ni fractions were collected in PFA beakers to which $\sim 5 \mathrm{~mL} 18.2 \mathrm{M} \Omega \mathrm{cm}$ water was added to prevent the formation of volatile tetracarbonylnickel (Victor, 1986). Acetone was evaporated at $75^{\circ} \mathrm{C}$ after which $\sim 300 \mu \mathrm{L}$ concentrated $\mathrm{HNO}_{3}$ was added and the solutions were evaporated to dryness. Repeated treatment with concentrated $\mathrm{HNO}_{3}$ and $30 \% \mathrm{H}_{2} \mathrm{O}_{2}$ largely eliminated the organic residue until only a clear green speck of Ni nitrate was left. The samples were then re-dissolved in $0.3 \mathrm{M} \mathrm{HNO}_{3}$ for measurement. Column yields are $>90 \%$; total procedural blanks are $0.4-0.8 \mathrm{ng}$ and thus negligible compared to the $\sim 5 \mu \mathrm{gi}$ used in the measurements.

\subsection{Mass spectrometry and data reduction}

Nickel isotope measurements were carried out using a Thermo Scientific Neptune multi-collector inductivelycoupled plasma mass spectrometer (MC-ICP-MS; s/n 1020). Samples were introduced in $0.3 \mathrm{M} \mathrm{HNO}_{3}$ with a 50 

$\sim 5 \mathrm{~mL} / \mathrm{min} \mathrm{N}_{2}$ ). The Neptune was operated in medium resolution $(\mathrm{m} / \Delta \mathrm{m} \geq 6000,5-95 \%$ peak height definition) in order to resolve isobaric interferences, notably ${ }^{40} \mathrm{Ar}^{18} \mathrm{O}$ on ${ }^{58} \mathrm{Ni}$ and minor oxide and argide complexes on other $\mathrm{Ni}$ isotopes (see online supplementary material). Interference of ${ }^{58} \mathrm{Fe}$ on ${ }^{58} \mathrm{Ni}$ could not be resolved but was corrected by monitoring ${ }^{56} \mathrm{Fe}$ and ${ }^{57} \mathrm{Fe}$. This correction was found to be robust at least up to ${ }^{56} \mathrm{Fe} /{ }^{60} \mathrm{Ni}=0.6$ while samples always had ${ }^{56} \mathrm{Fe} /{ }^{60} \mathrm{Ni}<0.15$ (supplementary Figure $\mathrm{S7}$ ).

Samples were measured at a concentration of $1 \mu \mathrm{g} / \mathrm{mL} \mathrm{Ni}$, which yielded a total Ni beam intensity (sample plus double spike) of 50-85 V on default $10^{11} \Omega$ amplifiers with an on-peak background of $<20 \mathrm{mV}$. A single measurement comprises 50 cycles of $4.2 \mathrm{~s}$ integration time, consuming $\sim 400 \mathrm{ng} \mathrm{Ni}$, preceded by an on-peak blank measurement of 15 cycles. Samples were bracketed with measurements of spiked reference material NIST SRM 986 as to allow a second-order correction of non-exponential instrumental mass fractionation. Data processing was carried out in an offline spreadsheet. After correction for the isobaric interference of $\mathrm{Fe}$, an outlier test was applied to exclude measurements outside 4 interquartile ranges of the median caused by memory effects in the Aridus. A blank subtraction was not applied as it was found to have a detrimental effect on the precision; blank corrected and uncorrected data proved identical within uncertainty with the latter being more precise. The double spike inversion yielded the ${ }^{60} \mathrm{Ni} /{ }^{58} \mathrm{Ni}$ of the sample that was expressed relative to the two adjacent SRM 986 measurements as $\delta^{60 / 58} \mathrm{NisRM} 986$ (hereafter written as $\delta^{60 / 58} \mathrm{Ni}$, following Coplen, 2011):

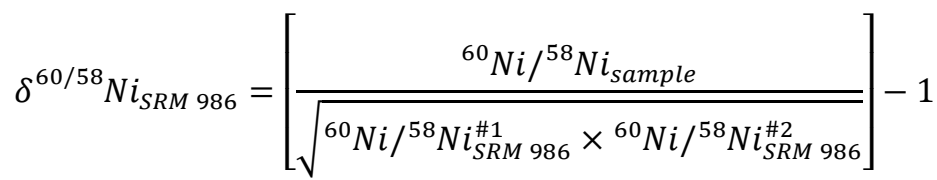
the standard error of the mean for the repeat measurements assuming homoscedasticity for each measurement session. No measurements were excluded at this stage. The reproducibility of the analytical protocol was evaluated through the repeated measurement of reference materials. Our in-house Bristol Isotope Group Ni solution (BIG-Ni) was measured both directly and after processing through the ion-exchange separation procedure, which yield indistinguishable means and an intermediate precision of $\delta^{60 / 58} \mathrm{Ni}=0.078 \pm$ $0.014 \%(2 s, n=29)$ over the course of this study (Figure 2a). Additionally, repeated measurements of reference materials JP-1 (dunite) and NIST SRM 361 (low alloy steel) yield $\delta^{60 / 58} \mathrm{Ni}=0.124 \pm 0.011 \%(2 \mathrm{~s}, \mathrm{n}=12$ ) and $-0.070 \pm 0.016 \%$ o $(2 s, n=9)$, respectively (Figure $2 \mathrm{a}$ ). The pooled intermediate precision for BIG-Ni, JP-1 and SRM 361 is $0.014 \%$, which we use as the best estimate of the uncertainty in our measurements. Indistinguishable values for processed and unprocessed BIG-Ni documents the robustness of the double spike method in correcting for any non-quantitative chemical separation yields and potential matrix effects caused by residual organic material from the dimethylglyoxime used to elute $\mathrm{Ni}$ (Klaver and Coath, 2019). 
anomalies are present. For meteoritic material, this is not the case (see discussion in section 5.3.1.). Hence, chondrite $\delta^{60 / 58} \mathrm{Ni}$ data need to be corrected for the presence of nucleosynthetic anomalies relative to the Earth. We follow the approach described by Hu and Dauphas (2017) using mass-independent Ni data compiled from Regelous et al. (2008), Steele et al. (2012), Tang and Dauphas (2012), Tang and Dauphas (2014) and Render et al. (2018). Chondrites are corrected using measured data for the same meteorite or the average for a meteorite class (e.g., EH). No mass-independent Ni data are available for CK chondrites (Karoonda). The average mass-independent composition of CV chondrites is used for correction of Karoonda as the similar $\mathrm{O}$ isotope composition of these two chondrite classes suggests that they are derived from the same parent body (Greenwood et al., 2010). The magnitude of the correction for nucleosynthetic anomalies on $\delta^{60 / 58} \mathrm{Ni}$ is $0.002-$ $0.003 \%$ for enstatite chondrites, $0.005-0.007 \%$ for ordinary chondrites, 0.005-0.016 \%o for carbonaceous chondrites except CR chondrites Renazzo and AI Rais (0.022\%; Table 2). All meteorite $\delta^{60 / 58} \mathrm{Ni}$ data reported in Tables 1 and 2, shown in the figures and discussed in the text is corrected for mass-independent anomalies.

\section{Results}

We obtain an intermediate precision of $0.014 \%(2 \mathrm{~s})$ on $\delta^{60 / 58} \mathrm{Ni}$ for BIG-Ni and reference materials JP-1 and SRM 361. This presents an improvement compared to previous double spike Ni studies that report a $2 \mathrm{~s}$ intermediate precision of 0.045 \%o (Gueguen et al., 2013) and 0.07 \%o (Gall et al., 2012; Gall et al., 2017) for geological reference materials. Compared to these studies, measuring higher intensity ion beams and multiple repeats per sample results in better counting statistics but our careful identification, resolution and monitoring of small but significant isobaric interferences (see supplementary material) may also play a role in our improved intermediate precision. Our $\delta^{60 / 58} \mathrm{Ni}$ results for low alloy steel SRM 361 and peridotite reference materials JP-1, DTS-1, DTS-2 and PCC-1 are in excellent agreement with literature data (Figure 2).

The $\delta^{60 / 58} \mathrm{Ni}$ data for peridotites and chondritic meteorites are listed in Tables 1 and 2, respectively, and shown in Figure 3. Terrestrial peridotites display a range in $\delta^{60 / 58} \mathrm{Ni}$ from 0.041 to $0.147 \%$ where the lower end of this distribution is formed by three peridotites with $\delta^{60 / 58} \mathrm{Ni}$ between 0.041 and $0.075 \%$. The 22 fertile to refractory peridotites yield a mean of $0.115 \pm 0.011 \%$ ( $\left.2 \mathrm{~s}_{\bar{x}}\right)$. Metasomatised peridotites have on average higher $\delta^{60 / 58} \mathrm{Ni}(0.108$ to $0.215 \%$ ) but only the heaviest sample, Zabargad Iherzolite BZ-230, overlaps with the $\mathrm{Ni}$ isotope compositions for the cratonic xenoliths reported by Gall et al. (2017; see Figure 4)

Chondrite $\delta^{60 / 58} \mathrm{Ni}$ results range from 0.024 to $0.278 \%$ o. Our enstatite chondrite measurements are most homogeneous whereas the carbonaceous chondrites display the largest variation. $\mathrm{Cl} 1$ chondrites have significantly lower $\delta^{60 / 58} \mathrm{Ni}$ than the other chondrites and two separate samples of Orgueil yield $\delta^{60 / 58} \mathrm{Ni}$ values $\sim 0.09 \%$ apart. Allende (CV3) and Karoonda (CK4) have the isotopically heaviest compositions of the carbonaceous chondrites. For Ceniceros (L3.7), three out of four microdrilled subsamples (5-10 mg) have identical $\delta^{60 / 58} \mathrm{Ni}$ to the bulk chip while subsample \#4 is around $0.04 \%$ lighter. The mean $\delta^{60 / 58} \mathrm{Ni}$ of the five measurements of Ceniceros, weighted by the mass of digested material, is $0.196 \pm 0.006$ (Table 2). Means for the three chondrite classes are indistinguishable: $\delta^{60 / 58} \mathrm{Ni}=0.213 \pm 0.026 \%$ for ordinary chondrites $(2 \mathrm{~s} \bar{x} ; n=7)$, 

excluding $\mathrm{Cl} 1$ chondrites). Taken together, all chondrites excluding $\mathrm{Cl} 1$ chondrites yield a mean $\delta^{60 / 58} \mathrm{Ni}$ of 0.212 $\pm 0.013 \%\left(2 s_{\tilde{x}} ; n=22\right)$.

\section{Discussion}

269

\section{1. $\mathrm{Ni}$ isotope systematics in the mantle}

Nickel isotope systematics in the mantle are relatively unexplored. The only study to date to report on the $\mathrm{Ni}$ isotope composition of a suite of peridotites is that of Gall et al. (2017), who found notable $\delta^{60 / 58} \mathrm{Ni}$ variations of $>0.1 \%$ in peridotite xenoliths from the Tanzania and Kaapvaal cratons. Based on a correlation between $\delta^{60 / 58} \mathrm{Ni}$ and modal clinopyroxene content (Figure 4), Gall et al. (2017) interpreted the range in $\delta^{60 / 58} \mathrm{Ni}$ to result from melt depletion, arguing that non-modal melting depletes the peridotite residue in isotopically heavy clinopyroxene. Given the small leverage of clinopyroxene on the $\mathrm{Ni}$ budget of peridotites, such a relationship is surprising. As $\mathrm{Ni}$ is a compatible element and therefore not likely to be sensitive to melt-rock reactions, Gall et al. (2017) did not consider the potential effects of post-melting events. Yet, their Tanzanian xenolith samples cannot be simple melting residues and show clear evidence for cryptic and modal metasomatism (Figure 1 and supplementary Figure S1; Dawson and Smith, 1973; Gibson et al., 2013). Our peridotite dataset covers a wider range from fertile to variably melt-depleted peridotites that are largely free from metasomatic overprints, complemented with five samples with different types of metasomatic overprint (Figure 1), which allows us to re-assess the influence of melt depletion and melt-rock reactions on $\mathrm{Ni}$ isotope systematics.

\subsubsection{Ni fractionation during melt extraction}

Fertile spinel- and garnet Iherzolites from Vitim and Tariat have geochemical compositions overlapping with those inferred for the primitive mantle (lonov et al., 2005; lonov, 2007; Kang et al., 2017; Carlson and lonov, 2019) while harzburgites in the Horoman massif represent the pristine residues of up $25 \%$ melt extraction (Takazawa et al., 2000). This large variation in degree of melt depletion is manifest as a range of modal clinopyroxene contents from $18 \%$ in the fertile samples to less than $1 \%$ in the most refractory samples. We observe no variation in $\delta^{60 / 58} \mathrm{Ni}$ as a function of modal clinopyroxene content, nor with other indices of depletion such as whole rock $\mathrm{Al}_{2} \mathrm{O}_{3}$ contents (Figure 4), which is in clear contrast with the conclusions reached by Gall et al. (2017). Olivine and orthopyroxene host $>90 \%$ of $\mathrm{Ni}$ in peridotites. As both these phases are retained during melting, $\delta^{60 / 58} \mathrm{Ni}$ of the residue is expected to be buffered as long as the olivine-melt and orthopyroxene-melt isotope fractionation factors do not greatly deviate from unity.

To illustrate the effects of melting on $\mathrm{Ni}$ isotope systematics, we have modelled the variation in $\delta^{60 / 58} \mathrm{Ni}$ of the solid residues and extracted melts (Figure 5). Mineral-olivine Ni isotope fractionation factors ( $\alpha_{\text {mineral-olivine})}$ are distilled from the mineral separate data of Gall et al. (2017), mineral-olivine Ni partition constants (D) are derived from Ni contents of phases in equilibrated fertile Vitim Iherzolites (Ionov et al., 2005) and we employed a variable Dmelt-olivine (8-30; Hart and Davis, 1978). The olivine-melt Ni isotope fractionation factor is the main 
unknown parameter in the modelling. Hence, we have explored a range of values for $\alpha_{\text {melt-olivine }}$ and used the values that reproduce the range in $\mathrm{Ni}$ isotope compositions reported for natural basalts. All modelling parameters are given in supplementary Table S4. An elemental and isotopic mass balance was applied to a pMELTS equilibrium melting model using a primitive mantle starting composition (Palme and O'Neill, 2014) to yield the $\delta^{60 / 58} \mathrm{Ni}$ of melt and residue, which is compared to the observed variations in peridotites (this study; Gall et al., 2017) and basalts (Cameron et al., 2009; Gueguen et al., 2013; Chernonozhkin et al., 2015).

Modelling confirms our inference that $\mathrm{Ni}$ isotopes do not noticeably fractionate in the mantle during melt depletion (Figure 5). The $\mathrm{Ni}$ isotope composition of melts is predominantly dependent on $\alpha_{\text {melt-olvine }}$ and the variation in natural basalts constrains $\alpha_{\text {melt-olivine }}$ to lie between 0.99985 and 1.00015 (Figure 5). Over this range in $\alpha_{\text {melt-olvine, }}$ the composition of residual peridotite remains constant within our level of precision $\left(\delta^{60 / 58} \mathrm{Ni}\right.$ $<0.015 \%$ o) up to very high degrees of melting. The $\delta^{60 / 58} \mathrm{Ni}$ of residual peridotite is insensitive to the value of

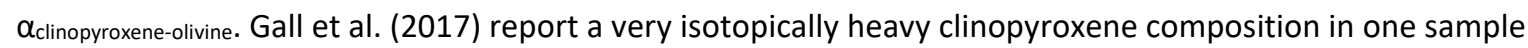

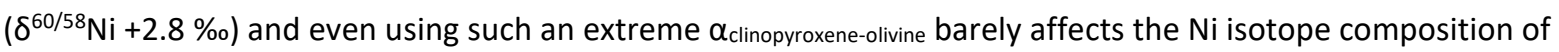
the residue as that is still dominated by olivine and orthopyroxene. A significant decrease in $\delta^{60 / 58} \mathrm{Ni}$ as the result of melt extraction, as proposed by Gall et al. (2017), can only be reproduced by adopting an $\alpha_{\text {melt-olivine }}$ that is an order of magnitude higher (1.001), which would result in very heavy Ni isotope compositions of mantle melts $\left(\delta^{60 / 58} \mathrm{Ni}>1 \%\right.$ ). This is clearly inconsistent with the data for natural basalts and hence we conclude that melt depletion does not fractionate $\mathrm{Ni}$ isotopes in the mantle and that the $\delta^{60 / 58} \mathrm{Ni}$ variations in the xenolith samples of Gall et al. (2017) results from a different process.

\subsubsection{The effects of metasomatism} Peridotite samples derived from the subcontinental lithospheric mantle often display evidence for interaction with percolating melts and fluids, leading to enrichment in incompatible elements and (re-)introduction of phases such as clinopyroxene and hydrous minerals (e.g., lonov et al., 2002; Grégoire et al., 2003; Simon et al., 2003; Pearson et al., 2014). The xenoliths measured for $\delta^{6 / 58} \mathrm{Ni}$ by Gall et al. (2017) have La/Sm and La contents higher than the primitive mantle (Figure 1 and supplementary Figure S1), which contrasts with their melt-depleted major element composition and suggests metasomatism by LREE-enriched melts. In addition, some of these samples have unusually high garnet and/or pyroxene contents while others contain late-stage phlogopite and ilmenite (Dawson and Smith, 1973; Gibson et al., 2013). We have measured four Tariat xenoliths and one Zabargad sample with clear evidence for metasomatic enrichment to investigate its effect on $\mathrm{Ni}$ isotope systematics. The metasomatised Tariat xenoliths have LREE-enriched compositions, in combination with the introduction of phlogopite in sample Mo4230-16, that results from silicate- and carbonatite melt metasomatism (Kang et al., 2017; Carlson and lonov, 2019). The hand specimen of Zabargad Iherzolite BZ-230 is enriched in clinopyroxene, which occurs in clusters that contain up to $30 \%$ clinopyroxene, and has an unusually heavy Li isotope signature, but no obvious LREE enrichment (Brooker et al., 2004). Three out of four metasomatised Tariat samples in our dataset have marginally higher $\delta^{60 / 58} \mathrm{Ni}$ than the pristine peridotites (Figure 3) but only the clinopyroxene-enriched Zabargad Iherzolite has a composition (0.215 \%o) that overlaps with the cratonic xenoliths of Gall et al., (2017; see Figure 4). In combination with the correlation between 
modal clinopyroxene and $\delta^{60 / 58} \mathrm{Ni}$ found by Gall et al. (2017), this suggests that $\mathrm{Ni}$ isotope systematics of peridotites are sensitive to the introduction of metasomatic clinopyroxene.

Clinopyroxene was found to be the isotopically heaviest phase in peridotite xenoliths $\left(\delta^{60 / 58} \mathrm{Ni}\right.$ up to 2.8 $\%$ ) by Gall et al. (2017). Equilibration between percolating melts and refractory peridotite is not expected to

343 significantly alter the $\mathrm{Ni}$ isotope composition of the peridotite as olivine and orthopyroxene will dominate the

$344 \mathrm{Ni}$ budget and hence buffer $\delta^{60 / 58} \mathrm{Ni}$, analogous to the arguments against $\mathrm{Ni}$ fractionation during melting in the

345 previous section. Trace element and Sr-Nd isotope evidence, however, indicates that metasomatic

346 clinopyroxene is often not in equilibrium with the other phases in the peridotite (e.g., Grégoire et al., 2003;

347 Simon et al., 2003; Carlson et al., 2004; Simon et al., 2007). In such a scenario, isotopically heavy clinopyroxene

348 can crystallise from a percolating melt without reaching equilibrium with the other phases and thus elevate the 349 bulk $\delta^{60 / 58} \mathrm{Ni}$ of the xenolith. Due to the low $\mathrm{Ni}$ content of metasomatic clinopyroxene (Gibson et al., 2013),

350 however, more than $20 \%$ of isotopically heavy clinopyroxene $\left(2.8 \%\right.$ ) has to be added to elevate $\delta^{60 / 58} \mathrm{Ni}$ of the 351 peridotite by $0.1 \%$, which is clearly in excess of the clinopyroxene modal abundances in the Gall et al. (2017)

352 samples (1-3 \% modal clinopyroxene; Figure 4). Hence, the disequilibrium introduction of clinopyroxene drives

353 a change in $\delta^{60 / 58} \mathrm{Ni}$ in the right direction but the variation in peridotites cannot be explained by the current

354 data. The significant difference in $\delta^{60 / 58} \mathrm{Ni}$ of clinopyroxene separates of Gall et al. (2017), however, might point 355 towards an even larger heterogeneity of clinopyroxene $\delta^{60 / 58} \mathrm{Ni}$ in metasomatised peridotites, which requires 356 further study to substantiate. We conclude that the correlation between modal clinopyroxene and $\delta^{60 / 58} \mathrm{Ni}$ in 357 metasomatised peridotites reflects a disequilibrium process where clinopyroxene is introduced without fully re358 equilibrating with the solid residue. Hence, $\delta^{60 / 58} \mathrm{Ni}$ in peridotites may be more susceptible to metasomatic 359 alteration than previously thought, yet the exact nature of the processes causing $\mathrm{Ni}$ isotope fractionation in the 360 mantle remain poorly constrained.

\subsubsection{Light Ni isotope compositions}

363 Three peridotite samples have lower $\delta^{60 / 58} \mathrm{Ni}$ than the majority of the samples (Figure 3). Dunite reference 364 material DTS-1 is also characterised by a light $\mathrm{Ni}$ isotope composition (-0.082 \%) that is distinct from its counterpart DTS-2, which also has a strikingly different Ni content (2360 versus 3780 ppm for DTS-1 and -2, respectively). Inhomogeneity and contamination of reference materials can be an issue and as we have no details on the processing of DTS-1, we exclude it from the subsequent discussion.

Weathering of ultramafic lithologies drives a decrease in $\delta^{60 / 58} \mathrm{Ni}$ in the solid residue (Ratié et al., 2015; Spivak-Birndorf et al., 2018), which is consistent with an isotopically heavy riverine flux and seawater composition (Cameron and Vance, 2014). This process will modify whole rock $\delta^{60 / 58} \mathrm{Ni}$ but should not affect the composition of unaltered olivine crystals, the main host of $\mathrm{Ni}$ in peridotites. If the light $\mathrm{Ni}$ isotope composition was already acquired in the mantle and the peridotites attained isotopic equilibrium, the $\mathrm{Ni}$ isotope composition of olivine is expected to mirror that of the bulk sample. Hence, to distinguish weathering from high-temperature processes as the cause of the light isotope compositions, we measured pristine handpicked olivine separates from the low- $\delta^{60 / 58} \mathrm{Ni}$ samples and two samples with normal $\delta^{60 / 58} \mathrm{Ni}$ (Figure 6). 
Olivine in all samples has similar $\delta^{60 / 58} \mathrm{Ni}$ to the bulk sample, which is consistent with olivine dominating the $\mathrm{Ni}$ budget in peridotites. The light isotope composition of the three samples is mirrored by low $\delta^{60 / 58} \mathrm{Ni}$ in olivine separates, thus clearly ruling out weathering as the processes responsible for the shift in $\delta^{60 / 58} \mathrm{Ni}$. Instead, these peridotites appear to have equilibrated at lower bulk $\delta^{60 / 58} \mathrm{Ni}$, which strongly points towards a high-temperature process that modified the $\mathrm{Ni}$ isotope composition in the mantle. There are few clues to the nature of this process as the low- $\delta^{60 / 58} \mathrm{Ni}$ samples are not distinct in any lithophile element systematics, as such effectively ruling out any form of silicate melt metasomatism. For instance, disequilibrium introduction of isotopically light orthopyroxene (Gall et al., 2017) should have been apparent from modal abundances and an elevated whole rock $\mathrm{SiO}_{2} / \mathrm{MgO}$, neither of which is observed.

The lack of any systematic variation in lithophile elements could point to a role for sulfide mobility, which can be decoupled from silicate melt metasomatism (e.g., van der Meer et al., 2017). The introduction of isotopically light sulfides (Gueguen et al., 2013; Hofmann et al., 2014) could lower $\delta^{60 / 58} \mathrm{Ni}$ while leaving lithophile elements unaffected. Tentative evidence for this process is provided by $\mathrm{S}$ contents that are significantly higher ( $\sim 10 \mathrm{ppm}$ ) than expected for the degree of depletion in low- $\delta^{60 / 58} \mathrm{Ni}$ Zabargad sample BZ241 (Brooker et al., 2004). No S abundance data are available for the Horoman samples, but petrographic and $\mathrm{Pb}$ isotope evidence suggest that sub-seafloor hydrothermal alteration in a mid-oceanic ridge setting has introduced Ni-rich sulfides in the Horoman peridotites (Ranaweera et al., 2018). The introduction of isotopically light pentlandite can elevate $\mathrm{S}$ contents and lower $\delta^{60 / 58} \mathrm{Ni}$ but need not lead to a noticeable increase in the abundance of lithophile elements. Adding $0.04 \%$ pentlandite ( $35 \mathrm{wt} . \% \mathrm{Ni}, \delta^{60 / 58} \mathrm{Ni}=-1 \%$ ), consistent with modal sulfide abundances (Ranaweera et al., 2018), and subsequent re-equilibration with the peridotite can account for the observed decrease in $\delta^{60 / 58} \mathrm{Ni}$ of $\sim 0.07 \%$. As such, sulfide metasomatism is the best candidate to explain a decrease in $\delta^{60 / 58} \mathrm{Ni}$ in these peridotites.

\section{2. $\mathrm{Ni}$ isotope systematics of chondrites}

The chondritic meteorites in this study display a significant degree of $\mathrm{Ni}$ isotope heterogeneity. Although there is no systematic difference between the range and average $\delta^{60 / 58} \mathrm{Ni}$ of ordinary and enstatite chondrites, carbonaceous chondrites are notably more heterogeneous (Figure 3). In particular, Cl1 type chondrites have significantly lower and more variable $\delta^{60 / 58} \mathrm{Ni}$ than other chondrite groups. When $\mathrm{Cl} 1$ chondrites are excluded (see discussion in 5.2.1.), however, the mean $\delta^{60 / 58} \mathrm{Ni}$ of carbonaceous chondrites is indistinguishable from enstatite and ordinary chondrites. Nevertheless, there is variation in $\delta^{60 / 58} \mathrm{Ni}$ outside analytical uncertainty within all chondrite classes. Previous studies have attributed $\mathrm{Ni}$ isotope heterogeneity in chondrites to variable proportions of isotopically heavy metal (Gall et al., 2017) or as the result of sorting of isotopically distinct silicate, metal and sulfide phases during accretion of the chondrite parent bodies (Moynier et al., 2007). We find no obvious correlation between $\mathrm{Ni}$ or metal content (Figure 7a) but note that metal separates from chondrites (Cook et al., 2007; Moynier et al., 2007) display a much larger variation than bulk chondrites (Figure

411 7a). Below, we will investigate processes that may contribute to the observed $\mathrm{Ni}$ isotope variation in chondrites. 
Petrological type 1 carbonaceous chondrites have experienced the largest extent of low-temperature aqueous alteration on their parent bodies (e.g., Richardson, 1978; Endress and Bischoff, 1993). Isotopic exchange with fluids is widely considered to be responsible for the heavier $\mathrm{O}$ isotope composition of $\mathrm{Cl} 1$ meteorites compared to other carbonaceous chondrite types (Figure 7b; Clayton and Mayeda, 1999). The Mg isotope composition of $\mathrm{Cl} 1$ chondrites is also shifted to heavier values compared to petrological type 2-6 chondrites (Hin et al., 2017), showing an overall consistent sense of fractionation caused by aqueous alteration. Nickel is a reasonably fluidmobile element that is isotopically fractionated during weathering in the terrestrial environment where the alteration of olivine to phyllosilicates causes a decrease in $\delta^{60 / 58} \mathrm{Ni}$ (Ratié et al., 2015; Spivak-Birndorf et al., 2018). Hence, alteration to a phyllosilicate-dominated mineralogy during aqueous alteration on the $\mathrm{Cl}$ parent body can help explain the overall lower $\delta^{60 / 58} \mathrm{Ni}$ in $\mathrm{Cl} 1$ chondrites

Not only are the values of $\delta^{60 / 58} \mathrm{Ni}$ in $\mathrm{Cl} 1$ chondrites low, but they are quite variable between different dissolution of the same meteorite (see Table 2, Steele et al., 2012 and Gall et al., 2017 for independent measurements of Orgueil that span $0.16 \%$ ). This marked isotopic variability echoes order of magnitude variation in Ni content in $\sim 100 \mu \mathrm{m}$ fragments of Cl1 chondrites (Morlok et al., 2006). The elemental heterogeneity in $\mathrm{Ni}$ exceeds that of $\mathrm{Fe}$ and in six large fragments of Orgueil, weighing $>0.6 \mathrm{~g}$, a variation of more than $10 \%$ in Ni content and $>20 \%$ in Fe/Ni was found by Barrat et al. (2012). The pronounced elemental and isotopic variability in $\mathrm{Ni}$ is likely related to the role of ferrihydrite, a phase that strongly adsorbs and isotopically fractionates Ni onto its surface (Eickhoff et al., 2014; Wasylenki et al., 2015). Ferrihydrite is a common fine-grained matrix phase that occurs intergrown with phyllosilicates in $\mathrm{Cl} 1$ chondrites, although its abundance is highly variable (e.g., Tomeoka and Buseck, 1988; Bland et al., 2004; King et al., 2015). Nickel and S contents correlate with the presence of ferrihydrite as a result of surface adsorption (Tomeoka and Buseck, 1988; Morlok et al., 2006). Experimental studies indicate that the adsorption of $\mathrm{Ni}$ onto ferrihydrite is associated with a fractionation of $\sim 0.35 \%$ in $\delta^{60 / 58} \mathrm{Ni}$ at room temperature (Wasylenki et al., 2015; Gueguen et al., 2018). As the abundance of ferrihydrite was found to vary from 2 to $5 \%$ in different subsamples of Orgueil (Bland et al., 2004; King et al., 2015), it is not surprising that we find both low and variable $\delta^{60 / 58} \mathrm{Ni}$ in our measurements of Orgueil. Given the highly specific role of ferrihydrite in influencing the $\mathrm{Ni}$ isotope composition of $\mathrm{Cl} 1$ chondrites, we do not include them in our average composition of carbonaceous chondrites.

\subsubsection{Ni diffusion during parent body metamorphism}

444 Parent body metamorphism causes notable redistribution of Ni between silicate, $\mathrm{Ni}$-bearing sulfide and metal phases during aqueous and thermal processing (e.g., Rubin, 1990; Huss et al., 2006). Fractionation of Ni isotopes can occur on a $\mu \mathrm{m}$ - to $\mathrm{mm}$-scale during diffusive transport of $\mathrm{Ni}$ between phases in response to changing equilibrium conditions. For example, $\mathrm{Ni}$ is redistributed between kamacite and taenite grains but, due to sluggish kinetics, does not reach equilibrium as illustrated by characteristic "M-shaped" Ni concentration profiles in taenite in chondrites (e.g., Wood, 1967). Modelling predicts that these frozen-in diffusion profiles are accompanied by kinetic fractionation of $\mathrm{Ni}$ isotopes (Dauphas, 2007; Watson et al., 2016), which is supported by up to $0.8 \%$ variations in $\delta^{60 / 58} \mathrm{Ni}$ in microdrilled iron meteorites that display similar diffusion 
profiles (Cook et al., 2007; Chernonozhkin et al., 2016). Moreover, a similar range of $\sim 0.8 \%$ in $\delta^{60 / 58} \mathrm{Ni}$ is observed in metal grains separated from ordinary chondrites by Moynier et al. (2007), which suggests that local $\mathrm{Ni}$ isotope disequilibrium is indeed prevalent in metal-bearing chondrites. The effects of kinetic fractionation in meteoritic metal are an order of magnitude larger than the observed variation within bulk ordinary and enstatites chondrites (Figure 7) and could contribute to scatter on the sampling scale. Whilst redistribution, and the potential for kinetic fractionation, of $\mathrm{Ni}$ between different meteoritic components during thermal metamorphism is best documented for ordinary chondrites (Rubin, 1990), it is likely to be significant in creating isotopic heterogeneity within chondrites more generally. For instance, perryite, a Ni silicide phase, disappears from the matrix of enstatite chondrites and $\mathrm{Ni}$ is partitioned into other phases including kamacite during thermal metamorphism on the enstatite chondrite parent body (Reed, 1968; Huss et al., 2006). Imperfect sampling of such heterogeneity can increase the variability in $\mathrm{Ni}$ isotope measurements of chondrites. To gauge the effect of these processes on measurements of samples the size typically used in this study, we compared the composition of a bulk sample of $\mathrm{L} 3.7$ chondrite Ceniceros to four subsamples that were microdrilled from two polished mounts. Three out of four microdrilled subsamples have a $\mathrm{Ni}$ isotope composition identical to the bulk chip whereas one subsamples is $0.04 \%$ lighter (Figure 3).

\subsection{Ni isotope fractionation during planetary differentiation}

\subsubsection{The Ni isotope composition of Earth's building blocks}

470 Nucleosynthetic (mass-independent) $\mathrm{Ni}$ isotope anomalies have been clearly established in iron meteorites, 471 bulk chondrites and CAls (e.g., Regelous et al., 2008; Steele et al., 2011; Steele et al., 2012; Tang and Dauphas, 2012; Render et al., 2018; Nanne et al., 2019; see Figure 8a). As these nucleosynthetic anomalies are not modified during the physicochemical processes of accretion and differentiation of the Earth, they serve as the most reliable geochemical proxy for the nature of the material accreting to from the Earth. Enstatite chondrites have a mass-independent $\mathrm{Ni}$ isotope composition that is the closest match to the Earth (Figure 9a). A similar picture emerges from all elements that have been investigated for nucleosynthetic anomalies (e.g., O, Cr, Ti, $\mathrm{Mo}, \mathrm{Ru}, \mathrm{Nd}$ ); from an isotopic perspective, the Earth is most similar, yet not an exact match, to enstatite chondrites (Warren, 2011; Dauphas, 2017). In particular, the fact that both lithophile and (highly) siderophile elements best match with enstatite chondrites provides key evidence that the nature of accreting material did not change significantly during the formation of the Earth and is unlikely to be a fortuitous mixture between ordinary chondrites and $\mathrm{Cl}$ chondrites (Dauphas, 2017). Recent high-precision Mo isotope measurements have been argued to allow some carbonaceous material in the later phases of accretion (Budde et al., 2019) but clearly exclude the possibility of a 2:1 ordinary chondrite-Cl chondrite mixture that might be permissible based on $\mathrm{Ni}$ isotope systematics alone (Figure 8a). For this reason, we take enstatite chondrites as the best proxy for the $\mathrm{Ni}$ isotopic composition of the building blocks of the Earth and explicitly compare the $\delta^{60 / 58} \mathrm{Ni}$ of the bulk silicate Earth to average enstatite chondrites. It must be noted that using a bulk chondrite value, excluding only the altered $\mathrm{Cl} 1$ chondrites, makes no difference within uncertainty to any of the conclusions reached here. 
491 The $\mathrm{Ni}$ isotope composition of the BSE is more contentious than that of chondrites (Figure $8 \mathrm{~b}$ ). Earlier $\delta^{60 / 58} \mathrm{Ni}_{\mathrm{BSE}}$ estimates were based on a small number of measurements of peridotitic and basaltic reference materials (Cameron et al., 2009; Steele et al., 2011; Gueguen et al., 2013; Elliott and Steele, 2017). The mantle hosts $49499.97 \%$ of $\mathrm{Ni}$ in the BSE and hence dominates its isotopic composition. Including basalts or komatiites, which might be fractionated relative to their mantle source depending on the at present unconstrained value of $\alpha_{\text {melt- }}$ olivine (Figure 5), can thus bias the estimated average $\delta^{60 / 58} \mathrm{NiBSE}$. This is compounded by potential inhomogeneity of reference materials and analytical artefacts in the measurement of low-Ni samples, as suggested by the different $\delta^{60 / 58} \mathrm{Ni}$ values reported for USGS reference material BHVO-2 with means varying outside quoted uncertainties by 0.2 \% (Cameron et al., 2009; Gall et al., 2012; Gueguen et al., 2013; Chernonozhkin et al., 2015; Render et al., 2018). In addition, including isotopically light dunite DTS-1 might skew the average towards lower $\delta^{60 / 58} \mathrm{Ni}$.

Gall et al. (2017) performed the first more systematic study of $\mathrm{Ni}$ isotopes in peridotites yet their sample set included several strongly metasomatised peridotites that may not be representative of the BSE and that biased their estimate of $\delta^{60 / 58} \mathrm{Ni}_{\text {BSE }}$ towards heavier isotope compositions $(0.23 \pm 0.06 \%$ ). By measuring a large suite of fertile and variably melt-depleted peridotites and explicitly investigating the effects of modal-and cryptic metasomatism on $\mathrm{Ni}$ isotope systematics, we have been able to provide a more precise and potentially more representative estimate of the Ni isotope composition of the BSE. Based on the absence of detectable fractionation as a function of degree of melt depletion, we take the average of all non-metasomatised peridotites to be representative of the BSE: $\delta^{60 / 58} \mathrm{Ni}_{\mathrm{BSE}}=0.115 \pm 0.011 \%$. As we observe no systematic variation in $\delta^{60 / 58} \mathrm{Ni}$ between different tectonic settings, facies (plagioclase, spinel and garnet) and degree of depletion (Figure 4) in the non-metasomatised peridotite samples, this is assumed to be a robust estimate of the composition of the BSE. Our average is in good agreement with published data for unmetasomatised peridotites (Figure 3); the discrepancy with previous estimates of the composition of the BSE mainly lies in the exclusion of basalts, komatiites and metasomatised peridotites.

Previous studies lacked the precision to resolve a difference in $8^{60 / 58} \mathrm{Ni}$ between the BSE and chondrites but hinted towards and isotopically light BSE (Figure 8a). By compiling all published data and optimistically using a 2s $\bar{x}$ uncertainty of the different reservoirs, Elliott and Steele (2017) suggested that the BSE has lower

$518 \delta^{60 / 58} \mathrm{Ni}$ than the chondritic reservoir. Our study substantiates their speculative inference and, for the first time, 519 documents a notable difference in $\delta^{60 / 58} \mathrm{Ni}$ between the BSE and Earth's building blocks (Figure 8a). Relative to enstatite chondrites, the BSE is lighter by $0.092 \pm 0.027 \%$. The observed difference is statistically significant; comparing all data for chondrites (excluding $\mathrm{Cl} 1$ ) and peridotites (see Figure 3 ) through a Mann-Whitney $U$ test indicates that the probability that the two groups are identical is $<<0.01$.

\subsubsection{A core formation signature?}

525 The notable non-chondritic Ni isotope composition of the BSE likely results from an isotopic fractionation event 526 on a planetary scale during the accretion and early differentiation of the Earth. Two main processes that can 527 shape the isotopic composition of the bulk Earth and its major reservoirs (core, BSE, atmosphere) are vapour 
loss during planetary accretion (e.g., Poitrasson et al., 2004; Pringle et al., 2014; Hin et al., 2017) and coremantle segregation (see Bourdon et al., 2018 for a recent review). Fractionation due to vapour loss will leave the bulk planet isotopically heavy, as for instance argued for Mg, Si and Cu (Georg et al., 2007; Savage et al., 2015; Hin et al., 2017). Vapour loss during accretion can therefore not account for the isotopically light $\mathrm{Ni}$ composition of the BSE and any evaporative fractionation of Ni would only result in an even larger difference in $\delta^{60 / 58} \mathrm{Ni}$ between the BSE and the core. The magnitude of evaporative fractionation of $\mathrm{Ni}$, however, is believed to be very small as modelling by Hin et al. (2017) predicts $<0.01 \% / \mathrm{u}$ fractionation for $\mathrm{Fe}$, which has a similar $50 \%$ condensation temperature (Lodders, 2003). Ruling out evaporative fractionation leaves core formation as the main candidate to have fractionated $\mathrm{Ni}$ on a planetary scale.

An isotopically enstatite chondrite bulk Earth with a mass distribution where $93 \%$ of the $\mathrm{Ni}$ is hosted in the core (McDonough, 2014) gives a difference in $\delta^{60 / 58} \mathrm{Ni}$ between the BSE and core, denoted as $\triangle^{60 / 58} \mathrm{NicoRE-BSE}$, of $0.099 \pm 0.029 \%$. Whether equilibrium isotope fractionation between the metallic core and silicate mantle can account for the observed difference is not clear due to the absence of comprehensive constraints from natural samples or experimental studies. A study of $\mathrm{Ni}$ isotopes in stony-iron meteorites yielded opposing signs for metal-silicate fractionation in mesosiderites and pallasites, suggesting that kinetic fractionation dominate over equilibrium effects (Chernonozhkin et al., 2016). The slow cooling of such samples allows subsolidus diffusion of $\mathrm{Ni}$ and associated non-equilibrium fractionation, making stony-iron meteorites inappropriate materials to study equilibrium metal-silicate fractionation.

Lazar et al. (2012) performed subsolidus experiments to determine the $\mathrm{Ni}$ isotope fractionation factor between $\mathrm{Ni}$ metal and $\mathrm{Ni}$-talc. Although these experiments are clearly not representative of the conditions of terrestrial core formation, they provide the only available experimental constraint on $\mathrm{Ni}$ fractionation between metal and silicate. The Lazar et al. (2012) experiments suggests that the metal phase preferentially hosts the heavier isotopes of $\mathrm{Ni}$, which is thus consistent with our observation of an isotopically light $\mathrm{BSE}$, yet the magnitude of fractionation is significantly smaller than the observed $\Delta^{60 / 58} \mathrm{NicORE-BSE}$ (Figure 9). At reasonable temperatures for terrestrial core formation (in excess of $2500^{\circ} \mathrm{C}$; e.g., Wade and Wood, 2005; Siebert et al., 2013; Fischer et al., 2015), the experimental calibration of Lazar et al. (2012) suggests negligible $(<0.02 \%)$ fractionation of $\mathrm{Ni}$ isotopes. Given how far removed from natural conditions the Lazar et al. (2012) experiments are, it is difficult to judge the significance of the discrepancy between the experimental constraints and observed $\Delta^{60 / 58} \mathrm{Ni}$ CORE-BSE. Superliquidus metal-silicate equilibrium experiments are required to gain a better understanding of metal-silicate fractionation of $\mathrm{Ni}$ as subtle compositional effects might influence its magnitude. A dependence of metal-silicate isotopic fractionation factors on the presence of minor alloying elements in the metal phase has been proposed for Fe (Shahar et al., 2015; Elardo and Shahar, 2017), although these results are controversial (cf., Poitrasson et al., 2009; Hin et al., 2012; Liu et al., 2017). Similar compositional effects might influence the isotopic fractionation of $\mathrm{Ni}$, making this a potentially interesting avenue to explore through experimental studies. In any case, our demonstration of a notably non-chondritic $\mathrm{Ni}$ isotope composition of the BSE provides an interesting new constraint on the conditions of terrestrial core formation, but significantly more experimental work is required to exploit this observation. 


\section{Conclusions}

568

569

570

571

572

573

574

575

576

577

578

579

580

581

582

583

584

585

586

587

588

589

590

591

592

593

594

595

596

597

598

599

600

601

602

603

We present a high-precision $\mathrm{Ni}$ isotope dataset for terrestrial peridotites and chondritic meteorites. The main findings of this work can be summarised as follows:

1) Mantle peridotites have a limited range in $\delta^{60 / 58} \mathrm{Ni}$ and do not exhibit systematic variation with degree of melt depletion. This is consistent with olivine and orthopyroxene dominating the Ni budget of residual peridotite, thus buffering the isotope composition. The composition of the BSE is constrained at $\delta^{60 / 58} \mathrm{Ni}=0.115 \pm 0.011 \%$.

2) Melt-metasomatised peridotites may show isotopically heavier compositions. Disequilibrium processes are required to increase $\delta^{60 / 58} \mathrm{Ni}$, which is otherwise buffered by olivine and orthopyroxene. The introduction of isotopically heavy clinopyroxene can drive an increase in $\delta^{60 / 58} \mathrm{Ni}$, but the exact nature of this process remains obscure.

3) Chondritic meteorites have more variable $\delta^{60 / 58} \mathrm{Ni}$, mainly as the result of heterogeneity at the sampling scale likely caused by parent body processes. Aqueous alteration and sorption of Ni onto ferrihydrite are responsible for the markedly isotopically light compositions of $\mathrm{Cl} 1$ chondrites. All other chondrites have notably higher $\delta^{60 / 58} \mathrm{Ni}$ than the BSE with a mean of $0.212 \pm 0.013 \%$.

4) The difference in $\delta^{60 / 58} \mathrm{Ni}$ between the BSE and chondrites is of the wrong sign to be caused by vapour loss during accretion and therefore likely results from terrestrial core formation. Experimental rationalisation is required to put the observation of an isotopically light BSE into context.

\section{Acknowledgements}

We would like to thank Richard Brooker for providing the Zabargad samples, Pieter Vroon for donating an aliquot of reference material PCC-1 and Rick Carlson who participated in collection and characterisation of Tariat xenoliths. Chris Coath is acknowledged for keeping the mass spectrometers in perfect working order whilst Roel van Elsas was of great help with mineral separation. Tu-Han Luu is thanked for providing the microdrilled meteorite samples. Stimulating discussions with Daan Hos, Edgar Steenstra and Remco Hin helped with interpretations of the data. The comments by associate editor Munir Humayun, Frank Poitrasson and two anonymous reviewers significantly helped to improve the manuscript. This work was funded by STFC through grant no. ST/M007715/1 and ERC AdG 321209 ISONEB.

\section{References}

Barrat, J.-A., Zanda, B., Moynier, F., Bollinger, C., Liorzou, C. and Bayon, G. (2012) Geochemistry of Cl chondrites: Major and trace elements, and $\mathrm{Cu}$ and $\mathrm{Zn}$ isotopes. Geochim. Cosmochim. Acta 83, 79-92. Bland, P.A., Cressey, G. and Menzies, O.N. (2004) Modal mineralogy of carbonaceous chondrites by X-ray diffraction and Mössbauer spectroscopy. Meteorit. Planet. Sci. 39, 3-16. 
Bourdon, B., Roskosz, M. and Hin, R.C. (2018) Isotope tracers of core formation. Earth-Science Reviews 181, 6181.

Brooker, R., James, R. and Blundy, J. (2004) Trace elements and Li isotope systematics in Zabargad peridotites: evidence of ancient subduction processes in the Red Sea mantle. Chem. Geol. 212, 179-204.

Budde, G., Burkhardt, C. and Kleine, T. (2019) Molybdenum isotopic evidence for the late accretion of outer Solar System material to Earth. Nature Astronomy 3, 736-741.

Buseck, P.R. and Holdsworth, E.F. (1972) Mineralogy and petrology of the Yilmia enstatite chondrite. Meteoritics 7, 429-448.

Cameron, V. and Vance, D. (2014) Heavy nickel isotope compositions in rivers and the oceans. Geochim. Cosmochim. Acta 128, 195-211.

Cameron, V., Vance, D., Archer, C. and House, C.H. (2009) A biomarker based on the stable isotopes of nickel. Proceedings of the National Academy of Sciences 106, 10944-10948.

Carlson, R.W. and Ionov, D.A. (2019) Compositional characteristics of the MORB mantle and bulk silicate earth based on spinel peridotites from the Tariat Region, Mongolia. Geochim. Cosmochim. Acta 257, 206-223.

Carlson, R.W., Irving, A.J., Schulze, D.J. and Hearn Jr, B.C. (2004) Timing of Precambrian melt depletion and Phanerozoic refertilization events in the lithospheric mantle of the Wyoming Craton and adjacent Central Plains Orogen. Lithos 77, 453-472.

Chernonozhkin, S.M., Goderis, S., Lobo, L., Claeys, P. and Vanhaecke, F. (2015) Development of an isolation procedure and MC-ICP-MS measurement protocol for the study of stable isotope ratio variations of nickel. J. Anal. At. Spectrom. 30, 1518-1530.

Chernonozhkin, S.M., Goderis, S., Costas-Rodríguez, M., Claeys, P. and Vanhaecke, F. (2016) Effect of parent body evolution on equilibrium and kinetic isotope fractionation: a combined $\mathrm{Ni}$ and Fe isotope study of iron and stony-iron meteorites. Geochim. Cosmochim. Acta 186, 168-188.

Clayton, R.N. and Mayeda, T.K. (1999) Oxygen isotope studies of carbonaceous chondrites. Geochim. Cosmochim. Acta 63, 2089-2104.

Cook, D.L., Wadhwa, M., Clayton, R.N., Dauphas, N., Janney, P.E. and Davis, A.M. (2007) Mass-dependent fractionation of nickel isotopes in meteoritic metal. Meteorit. Planet. Sci. 42, 2067-2077.

Coplen, T.B. (2011) Guidelines and recommended terms for expression of stable-isotope-ratio and gas-ratio measurement results. Rapid commun. mass spectrom. 25, 2538-2560.

Dauphas, N. (2007) Diffusion-driven kinetic isotope effect of Fe and Ni during formation of the Widmanstätten pattern. Meteorit. Planet. Sci. 42, 1597-1613.

Dauphas, N. (2017) The isotopic nature of the Earth's accreting material through time. Nature 541, 521-524.

Dauphas, N., Craddock, P.R., Asimow, P.D., Bennett, V.C., Nutman, A.P. and Ohnenstetter, D. (2009) Iron isotopes may reveal the redox conditions of mantle melting from Archean to Present. Earth Planet. Sci. Lett. 288, 255-267.

Dawson, J. and Smith, J. (1973) Alkalic pyroxenite xenoliths from the Lashaine volcano, northern Tanzania. J. Petrol. 14, 113-131. 
Eickhoff, M., Obst, M., Schröder, C., Hitchcock, A.P., Tyliszczak, T., Martinez, R.E., Robbins, L.J., Konhauser, K.O. and Kappler, A. (2014) Nickel partitioning in biogenic and abiogenic ferrihydrite: the influence of silica and implications for ancient environments. Geochim. Cosmochim. Acta 140, 65-79.

Elardo, S.M. and Shahar, A. (2017) Non-chondritic iron isotope ratios in planetary mantles as a result of core formation. Nat. Geosci. 10, 317-321.

Elliott, T. and Steele, R.C. (2017) The isotope geochemistry of Ni. Rev. Mineral. Geochem. 82, 511-542.

Endress, M. and Bischoff, A. (1993) Mineralogy, degree of brecciation, and aqueous alteration of $\mathrm{Cl}$ chondrites Orgueil, Ivuna, and Alais. Meteoritics 28, 345-346.

Fischer, R.A., Nakajima, Y., Campbell, A.J., Frost, D.J., Harries, D., Langenhorst, F., Miyajima, N., Pollok, K. and Rubie, D.C. (2015) High pressure metal-silicate partitioning of $\mathrm{Ni}, \mathrm{Co}, \mathrm{V}, \mathrm{Cr}, \mathrm{Si}$, and O. Geochim. Cosmochim. Acta 167, 177-194.

Fitoussi, C., Bourdon, B., Kleine, T., Oberli, F. and Reynolds, B.C. (2009) Si isotope systematics of meteorites and terrestrial peridotites: implications for $\mathrm{Mg} / \mathrm{Si}$ fractionation in the solar nebula and for Si in the Earth's core. Earth Planet. Sci. Lett. 287, 77-85.

Gall, L., Williams, H., Siebert, C. and Halliday, A. (2012) Determination of mass-dependent variations in nickel isotope compositions using double spiking and MC-ICPMS. J. Anal. At. Spectrom. 27, 137-145.

Gall, L., Williams, H.M., Halliday, A.N. and Kerr, A.C. (2017) Nickel isotopic composition of the mantle. Geochim. Cosmochim. Acta 199, 196-209.

Georg, R.B., Halliday, A.N., Schauble, E.A. and Reynolds, B.C. (2007) Silicon in the Earth's core. Nature 447, 1102-1106.

Gibson, S., McMahon, S., Day, J. and Dawson, J. (2013) Highly refractory lithospheric mantle beneath the Tanzanian craton: evidence from Lashaine pre-metasomatic garnet-bearing peridotites. J. Petrol. 54, 1503-1546.

Greenwood, R., Franchi, I., Kearsley, A. and Alard, O. (2010) The relationship between CK and CV chondrites. Geochim. Cosmochim. Acta 74, 1684-1705.

Grégoire, M., Bell, D. and Le Roex, A. (2003) Garnet Iherzolites from the Kaapvaal Craton (South Africa): trace element evidence for a metasomatic history. J. Petrol. 44, 629-657.

Gueguen, B., Rouxel, O., Ponzevera, E., Bekker, A. and Fouquet, Y. (2013) Nickel Isotope Variations in Terrestrial Silicate Rocks and Geological Reference Materials Measured by MC-ICP-MS. Geostand. Geoanal. Res. 37, 297-317.

Gueguen, B., Sorensen, J.V., Lalonde, S.V., Peña, J., Toner, B.M. and Rouxel, O. (2018) Variable Ni isotope fractionation between Fe-oxyhydroxides and implications for the use of $\mathrm{Ni}$ isotopes as geochemical tracers. Chem. Geol. 481, 38-52.

Hart, S.R. and Davis, K.E. (1978) Nickel partitioning between olivine and silicate melt. Earth Planet. Sci. Lett. 40, 203-219.

Hin, R.C., Schmidt, M.W. and Bourdon, B. (2012) Experimental evidence for the absence of iron isotope fractionation between metal and silicate liquids at $1 \mathrm{GPa}$ and $1250-1300 \mathrm{C}$ and its cosmochemical consequences. Geochim. Cosmochim. Acta 93, 164-181. 
Hin, R.C., Coath, C.D., Carter, P.J., Nimmo, F., Lai, Y.-J., von Strandmann, P.A.P., Willbold, M., Leinhardt, Z.M., Walter, M.J. and Elliott, T. (2017) Magnesium isotope evidence that accretional vapour loss shapes planetary compositions. Nature 549, 511-515.

Hofmann, A., Bekker, A., Dirks, P., Gueguen, B., Rumble, D. and Rouxel, O.J. (2014) Comparing orthomagmatic and hydrothermal mineralization models for komatiite-hosted nickel deposits in Zimbabwe using multiplesulfur, iron, and nickel isotope data. Mineral. Deposita 49, 75-100.

Hu, J.Y. and Dauphas, N. (2017) Double-spike data reduction in the presence of isotopic anomalies. J. Anal. At. Spectrom. 32, 2024-2033.

Huss, G.R., Rubin, A.E. and Grossman, J.N. (2006) Thermal metamorphism in chondrites, in: Lauretta, D.S., McSween Jr, H.Y. (Eds.), Meteorites and the Early Solar System II. University of Arizona Press, Arizona, pp. 567-586.

Ionov, D.A. (2007) Compositional variations and heterogeneity in fertile lithospheric mantle: peridotite xenoliths in basalts from Tariat, Mongolia. Contrib. Mineral. Petrol. 154, 455-477.

Ionov, D.A., Bodinier, J.-L., Mukasa, S.B. and Zanetti, A. (2002) Mechanisms and sources of mantle metasomatism: major and trace element compositions of peridotite xenoliths from Spitsbergen in the context of numerical modelling. J. Petrol. 43, 2219-2259.

Ionov, D.A., Ashchepkov, I. and Jagoutz, E. (2005) The provenance of fertile off-craton lithospheric mantle: Sr$\mathrm{Nd}$ isotope and chemical composition of garnet and spinel peridotite xenoliths from Vitim, Siberia. Chem. Geol. 217, 41-75.

Jarosewich, E. (1990) Chemical analyses of meteorites: A compilation of stony and iron meteorite analyses. Meteoritics 25, 323-337.

Kang, J.-T., lonov, D.A., Liu, F., Zhang, C.-L., Golovin, A.V., Qin, L.-P., Zhang, Z.-F. and Huang, F. (2017) Calcium isotopic fractionation in mantle peridotites by melting and metasomatism and Ca isotope composition of the Bulk Silicate Earth. Earth Planet. Sci. Lett. 474, 128-137.

King, A., Schofield, P., Howard, K. and Russell, S. (2015) Modal mineralogy of Cl and Cl-like chondrites by X-ray diffraction. Geochim. Cosmochim. Acta 165, 148-160.

Klaver, M. and Coath, C. (2019) Obtaining accurate isotopic compositions with the double spike technique: practical considerations. Geostand. Geoanal. Res. 43, 5-22.

Lai, Y.-J., von Strandmann, P.A.P., Dohmen, R., Takazawa, E. and Elliott, T. (2015) The influence of melt infiltration on the Li and $\mathrm{Mg}$ isotopic composition of the Horoman Peridotite Massif. Geochim. Cosmochim. Acta 164, 318-332.

Lazar, C., Young, E.D. and Manning, C.E. (2012) Experimental determination of equilibrium nickel isotope fractionation between metal and silicate from 500 C to 950 C. Geochim. Cosmochim. Acta 86, 276-295.

Li, J. and Agee, C.B. (1996) Geochemistry of mantle-core differentiation at high pressure. Nature 381, 686-689. Liu, J., Dauphas, N., Roskosz, M., Hu, M.Y., Yang, H., Bi, W., Zhao, J., Alp, E.E., Hu, J.Y. and Lin, J.-F. (2017) Iron isotopic fractionation between silicate mantle and metallic core at high pressure. Nature communications 8, 14377. 
Lodders, K. (2003) Solar system abundances and condensation temperatures of the elements. The Astrophysical Journal 591, 1220-1247.

Luu, T.-H., Hin, R., Coath, C. and Elliott, T. (2019) Bulk chondrite variability in mass independent magnesium isotope compositions - implications for initial solar system ${ }^{26} \mathrm{Al} /{ }^{27} \mathrm{Al}$ and the timing of terrestrial accretion. Earth Planet. Sci. Lett. 522, 166-175.

Mason, B. and Wiik, H.B. (1966) The composition of the Barratta, Carraweena, Kapoeta, Mooresfort, and Ngawi meteorites. American Museum Novitates 2273, 1-25.

McDonough, W. (2014) Compositional model for the Earth's core, in: Holland, H.D., Turekian, K.K. (Eds.), Treatise on geochemistry (2nd edition). Elsevier, Oxford, pp. 547-568.

Morlok, A., Bischoff, A., Stephan, T., Floss, C., Zinner, E. and Jessberger, E.K. (2006) Brecciation and chemical heterogeneities of $\mathrm{Cl}$ chondrites. Geochim. Cosmochim. Acta 70, 5371-5394.

Moynier, F., Blichert-Toft, J., Telouk, P., Luck, J.-M. and Albarède, F. (2007) Comparative stable isotope geochemistry of $\mathrm{Ni}, \mathrm{Cu}, \mathrm{Zn}$, and Fe in chondrites and iron meteorites. Geochim. Cosmochim. Acta 71, 4365-4379.

Nanne, J.A., Nimmo, F., Cuzzi, J.N. and Kleine, T. (2019) Origin of the non-carbonaceous-carbonaceous meteorite dichotomy. Earth Planet. Sci. Lett. 511, 44-54.

Palme, H. and O'Neill, H. (2014) Cosmochemical estimates of mantle composition, in: Holland, H.D., Turekian, K.K. (Eds.), Treatise on geochemistry (2nd edition). Elsevier, Oxford, pp. 1-39.

Pearson, D.G., Canil, D. and Shirey, S.B. (2014) Mantle Samples Included in Volcanic Rocks: Xenoliths and Diamonds, in: Holland, H.D., Turekian, K.K. (Eds.), Treatise on Geochemistry (2nd edition). Elsevier, Oxford, pp. 169-253.

Pogge von Strandmann, P.A., Elliott, T., Marschall, H.R., Coath, C., Lai, Y.-J., Jeffcoate, A.B. and lonov, D.A. (2011) Variations of Li and Mg isotope ratios in bulk chondrites and mantle xenoliths. Geochim. Cosmochim. Acta 75, 5247-5268.

Poitrasson, F., Halliday, A.N., Lee, D.-C., Levasseur, S. and Teutsch, N. (2004) Iron isotope differences between Earth, Moon, Mars and Vesta as possible records of contrasted accretion mechanisms. Earth Planet. Sci. Lett. 223, 253-266.

Poitrasson, F., Roskosz, M. and Corgne, A. (2009) No iron isotope fractionation between molten alloys and silicate melt to $2000 \mathrm{C}$ and 7.7 GPa: Experimental evidence and implications for planetary differentiation and accretion. Earth Planet. Sci. Lett. 278, 376-385.

Polyakov, V.B. (2009) Equilibrium iron isotope fractionation at core-mantle boundary conditions. Science 323, 912-914.

Pringle, E.A., Moynier, F., Savage, P.S., Badro, J. and Barrat, J.-A. (2014) Silicon isotopes in angrites and volatile loss in planetesimals. Proceedings of the National Academy of Sciences 111, 17029-17032.

Qi, Y.-H., Wu, F., Ionov, D.A., Puchtel, I.S., Carlson, R.W., Nicklas, R.W., Yu, H.-M., Kang, J.-T., Li, C.-H. and Huang, F. (2019) Vanadium isotope composition of the Bulk Silicate Earth: constraints from peridotites and komatiites. Geochim. Cosmochim. Acta 259, 288-301. 
Ranaweera, L.V., Ota, T., Moriguti, T., Tanaka, R. and Nakamura, E. (2018) Circa 1 Ga sub-seafloor hydrothermal alteration imprinted on the Horoman peridotite massif. Scientific reports 8, 9887.

Ratié, G., Jouvin, D., Garnier, J., Rouxel, O., Miska, S., Guimarães, E., Vieira, L.C., Sivry, Y., Zelano, I. and Montarges-Pelletier, E. (2015) Nickel isotope fractionation during tropical weathering of ultramafic rocks. Chem. Geol. 402, 68-76.

Reed, S. (1968) Perryite in the Kota-Kota and South Oman enstatite chondrites. Mineralogical Magazine and Journal of the Mineralogical Society 36, 850-854.

Regelous, M., Elliott, T. and Coath, C.D. (2008) Nickel isotope heterogeneity in the early Solar System. Earth Planet. Sci. Lett. 272, 330-338.

Render, J., Brennecka, G.A., Wang, S.-J., Wasylenki, L.E. and Kleine, T. (2018) A Distinct Nucleosynthetic Heritage for Early Solar System Solids Recorded by Ni Isotope Signatures. The Astrophysical Journal $\mathbf{8 6 2}$, 26.

Richardson, S.M. (1978) Vein formation in the C1 carbonaceous chondrites. Meteoritics 13, 141-159.

Rubin, A.E. (1990) Kamacite and olivine in ordinary chondrites: Intergroup and intragroup relationships. Geochim. Cosmochim. Acta 54, 1217-1232.

Saal, A., Takazawa, E., Frey, F., Shimizu, N. and Hart, S. (2001) Re-Os isotopes in the Horoman peridotite: evidence for refertilization? J. Petrol. 42, 25-37.

Savage, P.S., Moynier, F., Chen, H., Shofner, G., Siebert, J., Badro, J. and Puchtel, I. (2015) Copper isotope evidence for large-scale sulphide fractionation during Earth's differentiation. Geochemical Perspectives Letters 1, 53-64.

Schoenberg, R. and von Blanckenburg, F. (2006) Modes of planetary-scale Fe isotope fractionation. Earth Planet. Sci. Lett. 252, 342-359.

Shahar, A., Hillgren, V., Horan, M., Mesa-Garcia, J., Kaufman, L. and Mock, T. (2015) Sulfur-controlled iron isotope fractionation experiments of core formation in planetary bodies. Geochim. Cosmochim. Acta 150, 253-264.

Siebert, J., Badro, J., Antonangeli, D. and Ryerson, F.J. (2013) Terrestrial accretion under oxidizing conditions. Science 339, 1194-1197.

Simon, N.S., Irvine, G.J., Davies, G.R., Pearson, D.G. and Carlson, R.W. (2003) The origin of garnet and clinopyroxene in "depleted" Kaapvaal peridotites. Lithos 71, 289-322.

Simon, N.S., Carlson, R.W., Pearson, D.G. and Davies, G.R. (2007) The origin and evolution of the Kaapvaal cratonic lithospheric mantle. J. Petrol. 48, 589-625.

Spivak-Birndorf, L.J., Wang, S.-J., Bish, D.L. and Wasylenki, L.E. (2018) Nickel isotope fractionation during continental weathering. Chem. Geol. 476, 316-326.

Steele, R.C., Elliott, T., Coath, C.D. and Regelous, M. (2011) Confirmation of mass-independent Ni isotopic variability in iron meteorites. Geochim. Cosmochim. Acta 75, 7906-7925.

Steele, R.C., Coath, C.D., Regelous, M., Russell, S. and Elliott, T. (2012) Neutron-poor nickel isotope anomalies in meteorites. The Astrophysical Journal 758, 59. 
Takazawa, E., Frey, F., Shimizu, N. and Obata, M. (2000) Whole rock compositional variations in an upper mantle peridotite (Horoman, Hokkaido, Japan): are they consistent with a partial melting process? Geochim. Cosmochim. Acta 64, 695-716.

Tang, H. and Dauphas, N. (2012) Abundance, distribution, and origin of ${ }^{60} \mathrm{Fe}$ in the solar protoplanetary disk. Earth Planet. Sci. Lett. 359, 248-263.

Tang, H. and Dauphas, N. (2014) ${ }^{60} \mathrm{Fe}-{ }^{60} \mathrm{Ni}$ chronology of core formation in Mars. Earth Planet. Sci. Lett. 390, 264-274.

Tomeoka, K. and Buseck, P.R. (1988) Matrix mineralogy of the Orgueil Cl carbonaceous chondrite. Geochim. Cosmochim. Acta 52, 1627-1640.

van der Meer, Q.H., Klaver, M., Reisberg, L., Riches, A.J. and Davies, G.R. (2017) Preservation of an Archaean whole rock Re-Os isochron for the Venetia lithospheric mantle: Evidence for rapid crustal recycling and lithosphere stabilisation at 3.3 Ga. Geochim. Cosmochim. Acta 216, 242-263.

Victor, A. (1986) Separation of nickel from other elements by cation-exchange chromatography in dimethylglyoxime/hydrochloric acid/acetone media. Anal. Chim. Acta 183, 155-161.

Wade, J. and Wood, B. (2005) Core formation and the oxidation state of the Earth. Earth Planet. Sci. Lett. 236, 78-95.

Wahlgren, M., Orlandini, K. and Korkisch, J. (1970) Specific cation-exchange separation of nickel. Anal. Chim. Acta 52, 551-553.

Walter, M.J. (2014) Melt extraction and compositional variability in mantle lithosphere, in: Holland, H.D., Turekian, K.K. (Eds.), Treatise on geochemistry (2nd edition). Elsevier, Oxford, pp. 393-419.

Warren, P.H. (2011) Stable-isotopic anomalies and the accretionary assemblage of the Earth and Mars: A subordinate role for carbonaceous chondrites. Earth Planet. Sci. Lett. 311, 93-100.

Wasylenki, L.E., Howe, H.D., Spivak-Birndorf, L.J. and Bish, D.L. (2015) Ni isotope fractionation during sorption to ferrihydrite: implications for $\mathrm{Ni}$ in banded iron formations. Chem. Geol. 400, 56-64.

Watson, H.C., Richter, F., Liu, A. and Huss, G.R. (2016) Iron and nickel isotope fractionation by diffusion, with applications to iron meteorites. Earth Planet. Sci. Lett. 451, 159-167.

Weyer, S., Anbar, A.D., Brey, G.P., Münker, C., Mezger, K. and Woodland, A.B. (2005) Iron isotope fractionation during planetary differentiation. Earth Planet. Sci. Lett. 240, 251-264.

Weyer, S. and lonov, D.A. (2007) Partial melting and melt percolation in the mantle: the message from Fe isotopes. Earth Planet. Sci. Lett. 259, 119-133.

Williams, H.M., Wood, B.J., Wade, J., Frost, D.J. and Tuff, J. (2012) Isotopic evidence for internal oxidation of the Earth's mantle during accretion. Earth Planet. Sci. Lett. 321, 54-63.

Wood, J.A. (1967) Chondrites: Their metallic minerals, thermal histories, and parent planets. Icarus 6, 1-49.

Xia, J., Qin, L., Shen, J., Carlson, R.W., Ionov, D.A. and Mock, T.D. (2017) Chromium isotope heterogeneity in the mantle. Earth Planet. Sci. Lett. 464, 103-115.

\section{TABLE CAPTIONS}


829 Table 1. $\delta^{60 / 58} \mathrm{Ni}$ data for peridotites and geological reference materials. Data sources for $\mathrm{Ni}_{1} \mathrm{Al}_{2} \mathrm{O}_{3}$ and modal clinopyroxene contents are given in supplementary Table S1.

831

832

833

834

835

836

837

838

839

840

841

842

843

844

845

846

847

848

849

850

851

852

853

854

855

856

857

858

859

860

861

862

863

864

865

Table 2. $\delta^{60 / 58} \mathrm{Ni}$ data for chondritic meteorites.

\section{FIGURE CAPTIONS}

Figure 1. Compositional characterisation of the peridotite samples measured for their Ni isotope composition in this study: a) MgO versus primitive mantle-normalised La/Sm; b) $\delta^{25} \mathrm{Mg}$ versus $\delta^{7} \mathrm{Li}$. Open symbols depict metasomatised peridotites. The major and trace element composition of the primitive mantle (PM) is from Palme and O'Neill (2014); the Li and Mg isotope compositions of the PM are taken from Pogge von Strandmann et al. (2011) and Hin et al. (2017), respectively. Also shown as dark grey squares in a) are the compositions of xenoliths measured for $\mathrm{Ni}$ isotope composition by Gall et al. (2017) and other cratonic xenoliths (small grey circles). Data sources for the peridotite samples and cratonic xenoliths are listed in supplementary Table S1; the field for peridotite xenoliths and Li-Mg diffusion model in b) are from Pogge von Strandmann et al. (2011).

Figure 2. $\delta^{60 / 58} \mathrm{Ni}$ data relative to NIST SRM 986 for our in-house BIG-Ni solution and geological reference materials; a) intermediate precision for BIG-Ni (open symbols: BIG-Ni processed through the chemical separation procedure together with samples), dunite JP-1 and low alloy steel SRM 361. The lighter shaded bar displays the $2 \mathrm{~s}$ and the darker shaded bar the $2 \mathrm{~s}_{\bar{x}}$ precision. Processed- and unprocessed aliquots of BIG-Ni have identical means; b) comparison of geological reference materials to published results. Our data are in excellent agreement with published values yet more precise. High- and low-pressure digestions of DTS-1, the latter with minor residual spinel, yield indistinguishable $\delta^{60 / 58} \mathrm{Ni}$.

Figure 3. $\delta^{60 / 58} \mathrm{Ni}$ data for the measured peridotites and chondritic meteorites. Open symbols for peridotites represent samples affected by clear modal- or cryptic metasomatism. The open circles below the sample groups are published data for peridotites and chondritic meteorites (Cameron et al., 2009; Steele et al., 2012; Gueguen et al., 2013; Chernonozhkin et al., 2016; Gall et al., 2017). For ordinary chondrite Ceniceros (L3.7), both a bulk sample and four microdrilled subsamples were measured (see main text); the latter are shown as smaller. Error bars are $2 \mathrm{~s}$ intermediate precision for reference materials measured in this study; shaded fields represent the $95 \%$ confidence interval for the sample groups. For the peridotites, the metasomatised samples and DTS-1 are excluded from the mean; CI1 chondrites (stars) are excluded from the carbonaceous chondrite mean.

Figure 4. $\delta^{60 / 58} \mathrm{Ni}$ versus indices of degree of melt depletion: whole rock $\mathrm{Al}_{2} \mathrm{O}_{3}$ content (a) and modal clinopyroxene (b) for peridotites from this study and Gall et al. (2017). Data sources are listed in the online 
supplementary material. Open symbols are peridotites affected by cryptic- or modal and the shaded green bar depicts the $\delta^{6 / 58} \mathrm{Ni}$ of the $\mathrm{BSE}$ as determined in this study. The $\mathrm{Al}_{2} \mathrm{O}_{3}$ and modal clinopyroxene contents of the primitive upper mantle (PM) are from Palme and O'Neill (2014) and Walter (2014), respectively. Error bars are 2s for the Gall et al. (2017) data and smaller than symbol size for peridotites from this study.

870

Figure 5. Equilibrium melting of a primitive mantle source (Palme and O'Neill, 2014) with a $\delta^{60 / 58} \mathrm{Ni}$ of our new BSE estimate, using mineral-olivine Ni isotope fractionation factors from Gall et al. (2017) and mineral-olivine Ni partition coefficients derived from equilibrated fertile Vitim Iherzolites (Ionov et al., 2005). As $\alpha_{\text {melt-olivine is }}$ not constrained, the grey fields show modelled melt and residue compositions with $D_{\text {olivine-melt }}$ and $\alpha_{\text {melt-olivine }}$ varying from 8-30 and 0.99985-1.00015, respectively. All modelling parameters are given in supplementary Table S4. Modelled melt $\delta^{60 / 58} \mathrm{Ni}$ compositions are compared to literature data for basalts (Cameron et al., 2009; Gueguen et al., 2013; Chernonozhkin et al., 2015). Symbols for peridotite data, excluding the metasomatised and anomalously light samples, are as in previous figures; data from Gall et al. (2017) are shown as grey squares.

Figure 6. Comparison of whole rock (WR) versus olivine $\delta^{60 / 58} \mathrm{Ni}$ for five Horoman and Zabargad peridotites that include the anomalously light samples. The isotopically light compositions of these bulk peridotites is mirrored by pristine olivine separates, arguing against weathering or sample contamination as the cause of the lower $\delta^{60 / 58} \mathrm{Ni}$. See main text for further discussion.

Figure 7. $\mathrm{Ni}$ isotope variation in chondrites. a) lack of systematic variation of $\delta^{60 / 58} \mathrm{Ni}$ with $\mathrm{Ni}$ content; uncertainties are smaller than symbol size for our data. Literature data for ordinary (grey circles), enstatite (grey squares) and carbonaceous (grey diamonds) chondrites (Cameron et al., 2009; Steele et al., 2012; Chernonozhkin et al., 2016; Gall et al., 2017) are shown for comparison. Sources of Ni concentration data are listed in supplementary Table S1. The Ni isotope composition of metal separates from chondrites (Cook et al., 2007; Moynier et al., 2007) is shown as open circles on the right. Moynier et al. (2007) report their data relative to an Alfa Aesar Ni solution that has not been calibrated against SRM 986 and no data for other reference materials are given. In order to estimate the bias in the Moynier et al. (2007) data, we compared their results for iron meteorites Sikhote Alin and Gibeon to published values (Cook et al., 2007; Gueguen et al., 2013; Chernonozhkin et al., 2016; Gall et al., 2017) and found a systematic offset of $+0.089 \%$. We have therefore corrected their metal separate data down by $0.089 \%$, which results in a translation of all $\delta^{60 / 58} \mathrm{Ni}$ values but does not affect the magnitude of the variation found by Moynier et al. (2007); b) mass-dependent $O\left(\delta^{18} O\right)$ versus $\mathrm{Ni}$ isotope composition $\left(\delta^{60 / 58} \mathrm{Ni}\right)$ of carbonaceous chondrites; grey box shows the range of enstatite (EC) and ordinary chondrite compositions (OC). Oxygen isotope data are from Clayton and Mayeda (1999). A general covariation in $\delta^{18} \mathrm{O}$ and $\delta^{60 / 58} \mathrm{Ni}$ with degree of parent body low-temperature aqueous alteration (petrological type is colour coded) is observed. 
Figure 8. a) Nucleosynthetic (mass-independent) Ni anomalies of chondrites relative to the Earth. Data for the

904 chondrite classes are compiled from Regelous et al. (2008), Steele et al. (2012), Tang and Dauphas (2012, 2014)

905 and Render et al. (2018); the value for the Earth is from Steele et al. (2012) and the CAl array from Render et al.

906 (2018). The shaded fields show the composition of carbonaceous (CC) and non-carbonaceous (NC) type iron

907 meteorites (Steele et al., 2011; Nanne et al., 2019). The Earth is most similar to enstatite chondrites; see text

908 for discussion; b) The $\delta^{60 / 58} \mathrm{Ni}$ composition of the bulk silicate Earth (BSE) versus that of chondritic meteorites

909 from this study (enstatite chondrites only; black rectangle) and the literature (Cameron et al., 2009; Steele et

910 al., 2011; Steele et al., 2012; Gall et al., 2017). This study has sufficient resolution to provide the first robust

911 evidence that the BSE is isotopically light compared to the chondritic reservoir (top-left side of the diagram),

912 thus corroborating the inference by Elliott and Steele (2017) that was based on a compilation of literature data.

913

914 Figure 9. Experimental constraints on metal-silicate Ni isotope fractionation compared to the observed

$915 \Delta^{60 / 58} \mathrm{NiCORE-BSE}$. The blue diamonds are subsolidus experiments between Ni metal and talc from Lazar et al.

916 (2012); the blue shaded field shows their regression that excludes the experiment at $950^{\circ} \mathrm{C}$. The red shaded

917 bar at $2500-3500^{\circ} \mathrm{C}$ depicts plausible temperatures of core-mantle equilibration. See text for discussion. 